elegant analysis initiated our modern identification of information with negative entropy; it has since been taken further and made part of computing theory. It is now clear that Maxwell's Demon cannot possibly work.

Nanotechnological assemblers look suspiciously like Maxwell's Demons. Drexler's argument that they are "programmed, like infecting a bacterium with a virus", evades important questions about their thermodynamics and information flow. How do the assemblers get their information about which atom is where, in order to recognize and seize it? How do they know where they themselves are, so as to navigate from the supply dump to the correct position in which to place it? How will they get their power, for comminution to single atoms, navigation and, above all, for massive internal computing? How will they dispose of the entropy of their operations, and how much will they have to dispose of? The best modern computers still dissipate about $10^{12}$ times as much entropy as is theoretically needed by their information flow, so even allowing for improvements it could be quite a lot. Until these questions are properly formulated and answered, nanotechnology need not be taken seriously. It will remain just another exhibit in the freak-show that is the boundlessoptimism school of technical forecasting. $\square$

David E. H. Jones is in the Department of Chemistry, University of Newcastle upon Tyne, Newcastle upon Tyne NE1 7RU, UK.

\section{Proving the rule}

\section{Peter Lipton}

Killing Time: The Autobiography of Paul Feyerabend. By Paul Feyerabend. University of Chicago Press: 1995. Pp. 181. £18.25, \$22.95.

PAUL Feyerabend, who died in February last year, was the gadfly of the philosophy of science. Born and raised in Vienna, he fought for Germany during the Second World War, suffering bullet wounds to the spine that left him without effective use of his legs for the rest of his life. After the war, he returned to Vienna to study physics, with extensive philosophy and operatic singing on the side. Although much of Feyerabend's doctoral work was on a technical problem in classical electrodynamics, he ended up writing a philosophy thesis, for which he received a doctorate in 1951. He was then awarded a British Council scholarship to study with Wittgenstein in Cambridge, but had to find a different supervisor when Wittgenstein died the same year. He chose Karl Popper and became for a short time a card-carrying falsificationist. Soon, how- ever, he rejected Popper's philosophy of science with a vengeance, taking it as a model of how philosophy ought not to be done. In the long run, few contemporary philosophers of science managed to avoid Feyerabend's scorn.

Feyerabend's writings, best represented by Against Method (New Left Books, 1975), is a verbal blitzkrieg: aggressive, fast-moving and powerful. It is also enter-

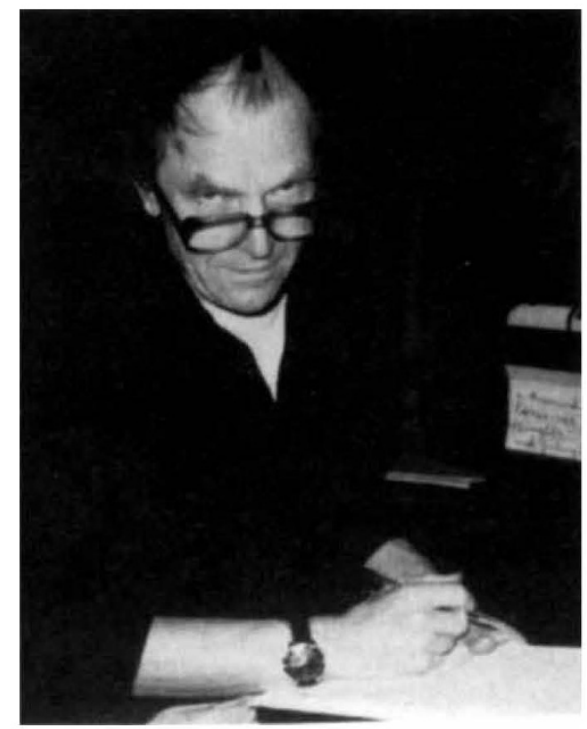

Feyerabend: science's worst enemy?

taining, infuriating and sometimes offensive. His primary target is the traditional philosophical project of explaining and defending scientific method. His strategy is to argue that any rules of scientific practice must be either so weak as to exclude nothing or persistently violated by the best scientific work. As he characteristically puts it: "The only principle that does not inhibit progress is: anything goes".

Feyerabend's attack on the very possibility of a non-trivial account of scientific practice comes in two stages. First he claims that the most basic methodological rules proposed by various philosophers of science were in fact broken in historical episodes that those philosophers themselves regard as models of science at its best, episodes that brought about the Copernican revolution, kinetic theory and quantum mechanics. The rules allegedly broken include those requiring that a new theory should be consistent with its predecessors or at least with the available evidence, that it should avoid ad hoc hypotheses and even that it should not be self-contradictory. The poor philosophers are themselves caught in a contradiction between the rules they invent and the science they admire.

The second stage of Feyerabend's attack on method deploys a variety of arguments to show that the violation of standard rules is not only a historical fact but is also essential to scientific progress. The arguments depend on two radical claims: that data are never independent of theory and that competing theories may be logically incommensurable. Feyerabend uses these claims to argue that a scientific theory cannot be evaluated by testing it against experiment and observation alone, but only by confronting it with radical alternatives. This case for theoretical pluralism gives Feyerabend the excuse to take his attack on the philosophers into overdrive, applying it to science itself. In this scheme, effective criticism involves confronting scientific theories with all sorts of nonscientific world views, however bizarre. And there is no presumption that conventional science ought to win out in the end.

Feyerabend's defence of voodoo is unlikely to impress many readers of Nature, but his case against the philosophical project of defining rules of scientific practice has considerable force. $\mathrm{He}$ certainly scores palpable hits against particular methodological prescriptions, especially those of a Popperian stripe. This does not, however, prove the negative. Showing the failures of one or another account of scientific method is not the same as showing that no successful account is possible. Moreover, even if scientific research does not lend itself to a rule-based description, the possibility of a general account remains because rules are not the only source of generality.

On this last point, Thomas Kuhn's Structure of Scientific Revolutions (University of Chicago Press, 1962) provides an excellent foil to Against Method. Kuhn and Feyerabend hold many radical views in common: scientific theories may be incommensurable, there are no facts independent of theory, and scientific research is not governed by rules. But the perceived absence of rules does not lead Kuhn to abandon the idea of a general account of scientific research. Instead, he replaces rule-based accounts of science with one based on the power of concrete problem-solutions or exemplars to guide research in the absence of explicit rules. Feyerabend's epistemological anarchy is not the only alternative to the view that there could be a rule-book of good scientific practice.

Feyerabend's autobiography includes some philosophy, but it is mostly an indiscreet reminiscence of the life and times of a wild philosopher. It makes entertaining reading and provides plenty of material about Feyerabend's early life for anyone who wants to attempt to give a psychological explanation for his later intellectual excesses. Readers interested in the provocative arguments themselves, however, are better off thickening their skins and reading Against Method.

Peter Lipton is in the Department of History and Philosophy of Science, University of Cambridge, Free School Lane, Cambridge CB2 3RH, UK. 